\title{
Knowledge of danger signs in newborns and health seeking practices of mothers and care givers in Enugu state, South-East Nigeria
}

\author{
Uchenna Ekwochi ${ }^{1 \dagger}$, Ikenna K Ndu ${ }^{1 \dagger}$, Chidiebere DI Osuorah ${ }^{2 *}$, Ogechukwu F Amadi ${ }^{1}$, Ifeyinwa B Okeke ${ }^{1}$, \\ Ejike Obuoha', Kenechi S Onah ${ }^{3}$, Ikenna Nwokoye ${ }^{4}$, Odutola I Odetunde ${ }^{5}$ and Nnenne I Obumneme-Anyim ${ }^{5}$
}

\begin{abstract}
Background: According to UNICEF, $40 \%$ of all under-5 deaths occur within the first month of life and half of these within the first few days of life. Many of these deaths are related to late recognition of neonatal illness, delays in decision to seek care at household level and subsequent late intervention at healthcare facilities. Knowledge of mothers about the danger signs in newborn is imperative to reduce these delays and preventable deaths.

Aim: This study aimed to assess the perception of mothers and/or care givers of danger signs in newborns and their knowledge of the WHO recognized danger. A secondary aim was to explore the socio-demographic factors of mothers that influence knowledge of the $\mathrm{WHO}$ recognized danger signs and the health seeking behaviors of these mothers and/or care-givers.

Methods: This was a community based descriptive and analytical study which used a multistage sampling technique to select 376 mothers and/or care-givers from four communities in 4 of the 17 Local Government Areas (LGA) of Enugu State. Logistic regression and chi-square was used in testing associations between variables.

Results: Knowledge of more than three of the nine WHO recognized danger sign was poor (0.0-30.3\%). Majority of the mothers had knowledge of one (i.e. fever) WHO recognized danger sign (95.2\%). Knowledge of the WHO signs was not significantly associated with maternal socio-demographic variables considered in this study. Healthcare seeking behaviour was significantly determined by knowledge of at least one WHO recognized danger sign (OR 4.6 Cl 1.1-18.7, $P=0.032$ ). Cough, diarrhea and the excessive crying were the most perceived and experienced non-WHO recognized dangers signs among respondents.
\end{abstract}

Conclusion: There is urgent need to strengthen the teaching and training of expectant mothers across all maternal socio-demographic variables on these danger signs and the most appropriate measures to take when they occur.

\section{Introduction}

The neonatal period (i.e. the first 28 days of life) is the most critical time for the survival of an infant. Despite the fact that global neonatal mortality rate has declined significantly by $40 \%$ between 1990 and 2013, this decline has not been in pace with the $56 \%$ decline of under- 5 mortality rate globally over the same period [1]. When stratified by regions and countries, this slow pace of neonatal mortality decline becomes bleak with the slowest

\footnotetext{
*Correspondence: chidi.osuorah@yahoo.com

'Equal contributors

${ }^{2}$ Child Survival Unit, Medical Research Council UK, The Gambia Unit, Fajara, Gambia

Full list of author information is available at the end of the article
}

pace of improvement recorded in Sub-Saharan Africa, South and East Asia. For instance, of the 86 million neonatal deaths recorded worldwide between 1990 and 2013, over $65 \%$ of them occurred in 10 countries in these regions with India and Nigeria accounting for $25 \%$ and $10 \%$ of these deaths respectively. According to a report in 2013, almost 2 million newborns died in the first week of life accounting for $73 \%$ of all neonatal deaths that year [2]. In Nigeria, the death of newborn babies accounts for more than $28 \%$ of all deaths in children before their $5^{\text {th }}$ birthday [3]. Though the highest absolute number of newborn deaths occurs in Asia due to the high birth rate and population in its countries, Africa still 
accounts for the highest national neonatal mortality rates seen around the world [4].

These disturbing statistics of neonatal mortality occurs because a newborn can die within minutes if prompt recognition, diagnosis and treatment are not initiated [5]. The modified three delays model [6] responsible for newborn death shows that household and health facility related delays were the major contributors to late presentation, treatment initiation and subsequent newborn deaths in many developing countries. These delays especially at the household level are particularly important because once there is a delay in the recognition of the danger signs of newborn illnesses there are automatically delays at all other levels i.e. initiation of appropriate treatment and/or referral to a better resourced hospital etc. Therefore, it becomes necessary to survey the knowledge of the signs which mothers in the developing country may perceive as "danger signs" (signs leading either to recognition of illness or heath care seeking) in the sick newborns. This study sought to determine what mothers in Enugu state perceive as danger signs and their knowledge of the WHO recognized danger signs. It further explored the socio-demographic features of mothers that influence knowledge of these danger signs and the health seeking behaviors of the mothers and/or care-givers.

\section{Methodology}

\section{Study area}

This study was conducted in Enugu state, the host town of Enugu State University of Science and Technology. It is located in south east Nigeria on latitude $6^{\circ} 27^{\prime} \mathrm{N}$ and longitude $7^{\circ} 30^{\prime} \mathrm{E}$ [7]. The state was nicknamed the coal city because coal mining activities were the driving force behind the city's growth in the 20th century. The economy of Enugu state is dependent mainly on national oil revenue and commerce. Enugu state is made up of 17 Local Government Areas (LGAs) with its capital carved from Enugu North, Enugu South and Enugu East Local Government Area. The majority of the inhabitants are Igbo by tribe, and Christianity is the dominant religion. The minimum monthly income, similar to the national average is $\$ 18,000$ (110 US\$). Literacy rate is $66 \%$, which is higher than the national literacy rate of $45 \%$, and there are 955 males per 1,000 females [8]. The fertility rate and neonatal mortality rate, similar to the national mean, are 4.5 births per woman and 40 per 1,000 live births respectively [8].

\section{Study subject and sampling technique}

This is a community based cross-sectional descriptive and analytical study. The data collection for this study was conducted over a 10 month period (from December 2013 to September 2014) in 4 of the 17 LGAs of Enugu
State. Multi-stage sampling method was used to select study participants. The list of the 17 LGAs of Enugu state was obtained from appropriate authorities. In order to obtain a representative sampling, the LGAs were divided into twelve rural and five semi urban categories based on level of development and population in the LGAs [8]. Simple random sampling using balloting method was used to select 2 LGAs from each category.

In the second stage, one community was selected from each LGA using simple random sampling (i.e. one community from each of the two rural and semi-urban LGA). A list of all the communities in the selected LGAs was compiled from the respective local government authorities. The communities of each LGA was numbered and folded into a medium to large sized container. An independent observer not involved in the research was requested to pick one folded paper at a time until four communities were chosen for the selected LGAs. After every pick, the selected paper was discarded and the container was shaken to ensure proper mixing of the remaining folded papers. This process was done separately for each of the 4 selected LGAs.

Based on the crude birth rate of $4.5 \%$ and a projected population of 3.5 million people in Enugu state [8] with an anticipated non-response rate of $15 \%$ and a $5 \%$ margin of error, a minimum of seventy-five (75) mothers were expected to be enrolled for this study. In each of the communities visited, through adequate mobilization using the community leaders, the women were asked to gather at a predetermined. Women who had babies less than 2 years of age and/or had nursed a baby in the past 2 years (in case of care givers) and consented to participate were consecutively enrolled and questionnaires administered. This process was repeated for each of the four communities visited. One hundred and five (105) women and care givers who met the inclusion criteria and gave consent to participate were selected for interview in each of the four communities giving a total of four hundred and twenty respondents from all four communities.

\section{Measures}

\section{Danger signs in newborns}

After obtaining oral informed consent, trained research assistants interviewed the mothers regarding newborn danger signs and actions they took when these danger signs were seen in their newborns. Mothers with children under-2 years old or care-givers who had nursed a child in the last two years where asked to list signs they considered serious health issues and could potentially endanger the life of a newborn. They were also requested to list any of these signs they have personally experienced, the initial actions they took, if they sought help from healthcare institution and reasons for not using healthcare facilities where 
appropriate. Mothers and/or care-givers were in addition asked to recall the time from noticing the danger sign(s) and presentation to the hospital, promptness of care in the health facility and final outcome of their newborn illness. The danger signs listed by mothers were organized and grouped into World Health Organization recognized danger signs [9] and the respondents perceived danger signs. The "WHO recognized dangers signs" based on WHO definition were categorized as follows: $i$ ) Not feeding since birth or stopped feeding; ii) Convulsion; iii) Respiratory rate of 60 or more (fast breathing); iv) Severe chest indrawing (difficulty in breathing); $v$ ) Temperature of $\geq 37.5$ degree centigrade (fever); vi) Temperature $\leq 35.5$ degree centigrade (hypothermia); vii) Only moves when stimulated or not even when stimulated (weakness or lethargy); viii) Yellow soles (sign of jaundice); $i x$ ) Umbilicus redness or draining pus, skin boils, or eyes draining pus (sign of local infection). Based on these, mothers were further categorized into the maximum number of WHO recognized danger signs known and correctly listed (see below).

\section{Socio-demographic characteristics}

i) Age of respondent: in years was assessed and grouped as 18-25, 26-30, 31-35 and 36+; ii) Educational attainment: was assessed using the highest level of education attained by respondents and grouped into no education, primary, secondary and tertiary education: iii) Place of residence: defined as the geographic location of the household was categorized as urban, and rural; iv) Marital status: of the surveyed women was originally grouped as "never married", "currently married" and "formerly married". These were re-coded into currently married for mothers in marriage and not married for mothers who have never or formerly married groups. v) Socioeconomic status: defined as the wealth index of the household was derived using maternal and paternal highest educational attainment and occupation based on oyedeji classification [10]. This was then categorized as lower, middle and upper class; vi) Number of children was defined as the number of children whether dead or alive that mother has given birth to or the number of children a care-giver has nursed prior to this study. They were classified into 1-4 and 4 or more;

\section{Data cleaning and analysis}

Quality control check was done by researchers on daily basis after enrollment and where errors were detected, the interviewers were asked to clarify them accordingly with the interviewed mother or care giver. Microsoft excel 2007 was used to input the raw data. Data cleaning was done by the research assistants and the study researchers. SPSS version 20 was used for data analysis. Chi-square and logistic regression statistical instrument were used to establish the relationship between knowledge of WHO recognized danger signs, mother's socio-demographic variables and seeking of healthcare service among mothers. Results were presented in percentages, odds ratios and 95\% confidence intervals where appropriate. Statistical significance was set at p-value $<0.05$.

\section{Result}

\section{Characteristic of respondents}

Four hundred and twenty mothers consented to participate in this study out of which 376 were successfully interviewed giving a recruitment fraction of $90 \%$. Of these, 196 (52.1\%) were resident in a rural and $180(47.9 \%)$ resident in a peri-urban area. A majority of the mothers had primary $(43.3 \%)$ and secondary school (31.8\%) as their highest educational attainment while $23(6.1 \%)$ and 72 (19.1\%) had no and post-secondary school education respectively. About $4 / 5^{\text {th }}$ of the mothers $(83.8 \%)$ were married and most (78.1\%) had 4 or fewer children. Slightly over half of the surveyed mothers (51.9\%) were in the low socioeconomic class with the remaining approximately evenly distributed between the middle (22.5\%) and upper (25.7\%) socio-economic class (Table 1).

\section{Danger signs: knowledge, perception and experience}

All but one of the mothers surveyed agreed they were aware of some signs in newborn suggestive of imminent danger. When asked to list those signs, 18 (4.8\%) had no knowledge of any and listed none. Majority (95.2\%) of the mothers listed correctly at least one of the WHO recognized danger signs. Two, three, four and five danger signs were correctly listed by 352 (93.6\%), 296 (78.7\%), 114 $(30.3 \%)$ and $50(13.2 \%)$ of the respondents respectively while only $11(2.9 \%)$ and $1(0.3 \%)$ correctly listed up to six and seven WHO recognized danger sign respectively (see Table 1). Two hundred and sixty three $(70.1 \%)$ of the respondent have or had previously noticed one or more of the danger signs in their current newborns and/or their older children when they were neonates. None of the maternal socio-demographic characteristics was significantly associated with knowledge of at least $1 \mathrm{WHO}$ recognized danger signs (Table 1).

Table 2 shows signs perceived by mothers as danger signs and those that mothers have actually experience in their current or previous newborns. Of the WHO recognized danger signs, fever 305 (25.4\%), refusal to feed 102 $(8.5 \%)$ and weakness $85(7.1 \%)$ were the most frequent signs mentioned as danger signs by the mothers. Others include convulsion 73 (6.1\%), "cold body" (i.e. hypothermia) 43 (3.6\%), yellowness of the body (i.e. jaundice) 41 (3.4\%), difficulty in breathing $35(2.9 \%)$, boil and/or rashes 30 (2.5\%) and fast breathing 20 (1.7\%). Mothers also mentioned signs perceived as dangers signs which are not WHO recognized. They include but were not limited to diarrhea 123 (10.3\%), excessive crying 98 (8.1\%), vomiting $81(6.8 \%)$ and abdominal colic $25(2.1 \%)$. Of all mothers 
Table 1 Summary description of respondents

\begin{tabular}{|c|c|c|c|c|}
\hline \multirow[t]{2}{*}{ Variables } & \multirow[t]{2}{*}{ n (\%) } & \multicolumn{2}{|c|}{$\begin{array}{l}\text { Knowledge of danger } \\
\text { signt }\end{array}$} & \multirow[t]{2}{*}{$P$-value } \\
\hline & & None & At least 1 & \\
\hline $\begin{array}{l}\text { Age of Mothers } \\
\text { (years) }\end{array}$ & $N=375$ & & & \\
\hline $18-25$ & $80(21.3)$ & $8(10.0)$ & $72(90.0)$ & 0.799 \\
\hline $26-30$ & $111(29.6)$ & $4(3.6)$ & $107(96.4)$ & \\
\hline $31-35$ & $68(18.1)$ & $2(3.0)$ & $65(97.0)$ & \\
\hline $36+$ & $116(30.9)$ & $3(2.6)$ & $112(97.4)$ & \\
\hline Completed Education & $N=376$ & & & \\
\hline None & $23(6.1)$ & $3(13.0)$ & $20(87.0)$ & 0.252 \\
\hline Primary & $163(43.3)$ & $7(4.3)$ & $154(96.6)$ & \\
\hline Secondary & 118 (31.4) & $4(3.4)$ & 114 (96.6) & \\
\hline Tertiary & $72(19.1)$ & $4(5.6)$ & $68(94.4)$ & \\
\hline Place of residence & $N=376$ & & & \\
\hline Rural & $196(52.1)$ & $8(4.1)$ & 187 (95.9) & 0.799 \\
\hline Urban & $180(47.9)$ & $10(5.6)$ & $169(94.4)$ & \\
\hline Currently married & $N=369$ & & & \\
\hline No & $54(14.6)$ & $15(4.8)$ & $299(95.2)$ & 0.748 \\
\hline Yes & $315(83.8)$ & $2(3.8)$ & $51(96.2)$ & \\
\hline Number of children & $N=370$ & & & \\
\hline 4 or less & $289(78.1)$ & $15(5.2)$ & $273(94.8)$ & 0.307 \\
\hline more than 4 & $81(21.9)$ & $2(2.5)$ & 78 (97.5) & \\
\hline $\begin{array}{l}\text { Socioeconomic } \\
\text { Status }\end{array}$ & $N=374$ & & & \\
\hline Lower & $194(51.9)$ & $6(3.1)$ & $187(96.9)$ & 0.265 \\
\hline Middle & $84(22.5)$ & $4(4.8)$ & $80(95.2)$ & \\
\hline Upper & $96(25.7)$ & $7(7.4)$ & $88(92.6)$ & \\
\hline $\begin{array}{l}\text { Experience of } \geq 1 \\
\text { sign in newborn }\end{array}$ & $N=375$ & & & \\
\hline No & $112(29.9)$ & $10(3.8)$ & $252(96.2)$ & 0.292 \\
\hline Yes & $263(70.1)$ & $7(6.3)$ & $104(93.7)$ & \\
\hline $\begin{array}{l}\text { Knowledge of } \\
\text { danger signst }\end{array}$ & $N=376$ & & & \\
\hline None & $18(4.8)$ & & & \\
\hline At most 1 & $358(95.2)$ & & & \\
\hline At most 2 & 352 (93.6) & & & \\
\hline At most 3 & $296(78.7)$ & & & \\
\hline At most 4 & $114(30.3)$ & & & \\
\hline At most 5 & $50(13.2)$ & & & \\
\hline At most 6 & $11(29.3)$ & & & \\
\hline At most 7 & $1(0.3)$ & & & \\
\hline At most 8 & $0(0.0)$ & & & \\
\hline All 9 & $0(0.0)$ & & & \\
\hline
\end{tabular}

tWHO recognized danger signs in newborns. who have experienced these signs in their newborns (current or previous), fever 114 (30.9\%), convulsion 18 (4.8\%) and jaundice 14 (3.7\%) were the commonest WHO recognized danger signs that have been experienced by the mothers while cough 29 (7.7\%), diarrhea 20 (5.3\%) and the excessive crying $14(3.7 \%)$ were the most frequent perceived danger signs experienced by mothers (Table 2 ).

\section{Danger signs: interventions and health seeking behaviors}

Of the 263 mothers and/or care-givers who have experienced the perceived and WHO recognized danger signs in their newborns approximately half of these mothers $125(47.7 \%)$ took the child to the hospital immediately without any home intervention. Five $(1.9 \%)$ of these mothers did nothing while the remaining 133 (50.5\%) did the following: $13(5.0 \%)$ used glucose water, 84 (32.1\%) gave over the counter medications (self medication), 12 (4.6\%) used local concoction and/or traditional medications and 24 (8.8\%) used other interventions. These 'other' interventions used included tepid sponging for fever, bathing with rice water for boils/rash, exposure to sunlight for jaundice, rubbing of coconut oil for cold body, giving gripe water for abdominal colic, giving palm-oil for convulsion, applying pepper on body for weak or lethargic newborns to stimulate activity etc. After initial and various intervention 202 (76.8\%) and 61 (16.2\%) did and did not take their newborn to the hospital respectively. For those who did, close to two-fifth (45\%) presented to the hospital more than 24 hours after recognition of the danger signs. More mothers without knowledge of these danger signs presented to hospital later than 24 hours after onset of newborns illness. This however failed to attain statistical significance $(P=0.073)$. Among the 61 mothers who did not present to the hospital at all, the most frequent reasons for not taking newborn to the hospital given by the respondents included; symptoms resolved $(40.8 \%)$, cost and/or inaccessibility of healthcare facilities (13.1\%), lack of knowledge of signs (11.4\%) and no reason (29.5\%). Others include perceived low care in healthcare facility (1.6\%), traditional and/or religious faith (1.6\%) and lack of decision autonomy to seek healthcare for newborn (1.6\%). Only knowledge of at least one WHO recognized danger sign significantly determined seeking of healthcare in a medical facility in sick newborn $(P=0.005)$ (Table 3$)$. Logistic regression analysis showed that mothers with knowledge of at least one danger sign were more likely to seek healthcare services compared to those with no knowledge of these dangers signs (OR 4.6 CI 1.1-18.7, $P=0.032$ ), (Table 3).

\section{Discussion}

The study revealed that knowledge of at least one danger sign in the newborn considerably increased the likelihood of mother and/or caregiver to seek care in health 
Table 2 Recognition of the danger signs and consequent healthcare-seeking behavior

\begin{tabular}{|c|c|c|c|c|}
\hline \multirow[t]{3}{*}{ Signs } & \multicolumn{2}{|c|}{ Danger signst ${ }^{1} \mathrm{n}(\%)$} & \multicolumn{2}{|c|}{ Sought medical care subsequent to experience } \\
\hline & Perceived & Experienced & Yes & No \\
\hline & $N=1199$ & $N=263$ & $N=202$ & $N=61$ \\
\hline Weakness $t^{2}$ & $85(7.1)$ & $7(1.9)$ & $5(71.4)$ & $2(28.6)$ \\
\hline Fever $t^{2}$ & $305(25.4)$ & 114 (30.9) & $94(82.5)$ & $20(17.5)$ \\
\hline Excessive crying & $97(8.1)$ & $14(3.7)$ & $9(64.3)$ & $5(35.7)$ \\
\hline Vomiting & $81(6.8)$ & $13(3.5)$ & $11(86.6)$ & $2(15.4)$ \\
\hline Refusal to feed $t^{2}$ & $102(8.5)$ & $4(1.1)$ & $3(75.0)$ & $1(75.0)$ \\
\hline Difficulty in breathing $t^{2}$ & $35(2.9)$ & $9(2.4)$ & $8(88.9)$ & $1(11.1)$ \\
\hline Diarrhea & $123(10.3)$ & $20(5.3)$ & $14(70.0)$ & $6(30.0)$ \\
\hline Jaundice $t^{2}$ & $41(3.4)$ & $14(3.7)$ & $11(78.6)$ & $3(21.4)$ \\
\hline Cough & $97(8.1)$ & $29(7.7)$ & $23(79.3)$ & $6(20.7)$ \\
\hline Convulsion $t^{2}$ & $73(6.1)$ & $18(4.8)$ & $13(72.2)$ & $5(27.8)$ \\
\hline Cold body $t^{2}$ & $43(3.6)$ & $2(0.5)$ & $2(100.0)$ & $0(0.0)$ \\
\hline Boil and/or rash $t^{2}$ & $30(2.5)$ & $8(2.1)$ & $5(62.5)$ & $3(37.5)$ \\
\hline Abdominal colic & $25(2.1)$ & $3(0.8)$ & $1(33.3)$ & $2(66.7)$ \\
\hline Catarrh & $21(1.8)$ & $4(1.1)$ & $2(50.0)$ & $2(50.0)$ \\
\hline Fast breathing $t^{2}$ & $20(1.7)$ & $3(0.8)$ & $1(33.3)$ & $2(66.7)$ \\
\hline Bulging Fontanel & $1(0.1)$ & $1(0.3)$ & $0(0.0)$ & $1(100.0)$ \\
\hline LBW/ Prematurity & $2(0.2)$ & $0(0.0)$ & $0(0.0)$ & $0(0.0)$ \\
\hline Inability to stool & $5(0.4)$ & $0(0.0)$ & $0(0.0)$ & $0(0.0)$ \\
\hline Abdominal distension & $6(0.5)$ & $0(0.0)$ & $0(0.0)$ & $0(0.0)$ \\
\hline Headache (Hotness of head) & $7(0.6)$ & $0(0.0)$ & $0(0.0)$ & $0(0.0)$ \\
\hline
\end{tabular}

$\dagger^{1}$ minimum and maximum danger signs listed by respondents were 1 and 7 respectively; $\dagger^{2}$ WHO recognized danger signs in newborn [9].

facilities. Even though the proportion of mothers with at least one danger sign knowledge compared to those with none is skewed towards the former, this is hardly surprising as knowledge of signs signifying imminent danger will in many cases logically evoke a quicker response to seek healthcare services, consequently increasing the chances of child survival. This early response and presentation to the hospital has been documented as an important factor in reduction of neonatal mortality in emergency situation $[11,12]$. This reiterates the need for renewed and intensive education of mothers about these signs during pregnancy and antenatal care visits in order to minimize the delays in initial household interventions and decision to seek care.

The study further showed that a majority (95.2\%) of the respondents had knowledge of one WHO recognized danger sign and those with knowledge of two and three danger signs were also considerably high $(93.2 \%$ and $78.7 \%$ respectively). This high knowledge of few danger signs amongst respondents was corroborated by a similar study in rural India where $67.2 \%$ of respondents had knowledge of at least one danger sign in newborns [13]. Though these figures are commendable, the proportion with knowledge of more than three danger signs drastically reduced from $30.3 \%$ to $0.3 \%$ with none having knowledge of up to 8 or all of the WHO recognized danger signs. A similar reduction in proportion of mothers with knowledge of more than one danger signs in newborns was also noted in studies conducted in Uganda, India and Bangladesh [14-16]. Though there is no universal accepted standard in relation to the number of danger signs that constitute adequate knowledge, it is nonetheless fair to say that knowledge of one or two danger signs out of nine recognized dangers does not suffice for adequate knowledge. The implication of this poor knowledge was reflected in the fraction of mothers with experience of these signs in their sick newborn who sought care in health facilities immediately the danger signs were observed in this study. Less than half $(47.7 \%)$ presented to the hospital immediately these signs were noticed and about one in four (23\%) did not present to the hospital at all following the delays at the household level. This delay will inadvertently result in late presentation to hospital and subsequent late administration of appropriate interventions resulting in mortality. This trend is particularly disturbing especially in Nigeria with one of the worst neonatal mortality rates in the Africa and among the highest in the world. 
Table 3 Analysis of respondent's healthcare seeking behavior for newborn with danger signs

\begin{tabular}{|c|c|c|c|c|}
\hline Variables & Sought healthcare $n(\%)$ & $P$-value & Odd ratio OR $(95 \% \mathrm{Cl})$ & $P$-value \\
\hline \multicolumn{5}{|l|}{ Mothers age (years) } \\
\hline $18-25$ & $39(67.2)$ & 0.181 & $1.9(0.7-4.8)$ & 0.196 \\
\hline $26-30$ & $62(81.6)$ & & $0.9(0.4-2.4)$ & 0.892 \\
\hline $31-35$ & $34(73.9)$ & & $1.5(0.6-3.9)$ & 0.429 \\
\hline $36+$ & $67(80.7)$ & & 1 & - \\
\hline \multicolumn{5}{|l|}{ Completed Education } \\
\hline None & $9(60.0)$ & 0.234 & 1 & - \\
\hline Primary & $89(76.1)$ & & $2.8(0.8-9.7)$ & 0.097 \\
\hline Higher (secondary \pm tertiary) & $104(79.4)$ & & $1.2(0.7-2.3)$ & 0.591 \\
\hline \multicolumn{5}{|l|}{ Place of residence } \\
\hline Rural & $119(74.8)$ & 0.351 & 1 & - \\
\hline Urban & $83(79.8)$ & & $1.3(0.5-3.5)$ & 0.652 \\
\hline \multicolumn{5}{|l|}{ Currently married } \\
\hline No & $34(82.9)$ & 0.313 & 1 & - \\
\hline Yes & $165(75.7)$ & & $1.8(0.6-4.9)$ & 0.294 \\
\hline \multicolumn{5}{|l|}{ Number of children } \\
\hline 4 or less & $148(77.5)$ & 0.676 & 1 & - \\
\hline more than 4 & $51(75.1)$ & & $1.5(0.7-3.3)$ & 0.272 \\
\hline \multicolumn{5}{|l|}{ Socioeconomic Status } \\
\hline Lower & $116(75.8)$ & 0.410 & 1 & - \\
\hline Middle & $44(73.3)$ & & $2.8(0.8-9.7)$ & 0.562 \\
\hline Upper & $41(83.7)$ & & $1.2(0.6-2.3)$ & 0.686 \\
\hline \multicolumn{5}{|l|}{ Knowledge of danger signs } \\
\hline None & $4(40.0)$ & $0.005+$ & 1 & - \\
\hline At least 1 & 197 (78.2) & & $4.6(1.1-18.7)$ & $0.032 \dagger$ \\
\hline
\end{tabular}

†-Statistically significant.

Perhaps because of the almost non subjective nature and/or the ease of being easily detected, fever, refusal to feed and weakness were and importantly so, the most frequently listed WHO recognized danger signs and also prompted the most healthcare facility visits by respondents. Similarly, cough and diarrhea which are features of the leading cause of child death and potentially fatal illnesses in newborn and excessive crying which could be an unspecific signal for other danger sign in newborns were the most perceived (non-WHO recognized) danger signs that prompted hospital visit among respondents. Other studies $[12,14]$ have documented these signs and others which are non WHO recognized as highly perceived as danger signs amongst mothers. The National Neonatology Forum of India (NNF) recognizing this, has included them as danger signs in its newborn training manual [17]. Though not WHO recognized, some of these signs as identified [18] are indicators of leading causes of morbidity and mortality in newborns and should be considered in any danger sign list in developing countries.
Finally, apart from knowledge of at least one danger sign, most maternal variables recognized as favorable determinants of child survival (i.e. maternal education, age and higher socio-economic status) were not significantly associated with knowledge of WHO designated danger signs and subsequent decision to seek care. There is therefore urgent need to incorporate and/or consolidate the teaching of expectant mothers during ANC on these danger signs. This teaching should specifically focus on how to recognize danger signs and the most appropriate action to take especially in rural communities where expert medical help may not be within immediate reach.

Competing interests

The authors declare that they have no competing interests.

Authors' contributions

Research idea was conceived by EU and NK. All authors contributed in the questionnaire design. $\mathrm{NI}, \mathrm{AFO}, \mathrm{OBI}$ and $\mathrm{OIN}$ supervised and assisted in data collection and field work. Abstract, Introduction, data analysis and the result section were written by ODIC. The study methodology was designed by 
ODIC, EU, NK, OE, OIO and OSK. Discussion was written with contribution

from all authors. All authors read and approved the final manuscript.

\section{Acknowledgements}

The authors wish to express our gratitude to all medical students who worked as research assistants during the field work. Also wish to thank the leaders and members of the following communities for participating in the research: Ndi-Uno Uwani Akpugo, Nkanu West LGA; Nomeh, Nkanu East LGA; Uwani, Enugu South LGA and Abakpa Nike, Enugu North LGA all of Enugu State, Nigeria

\section{Author details}

'Department of Paediatrics, Enugu State University of Science and Technology, Enugu, Enugu State, Nigeria. ${ }^{2}$ Child Survival Unit, Medical Research Council UK, The Gambia Unit, Fajara, Gambia. ${ }^{3}$ Department of Paediatrics, Nnamdi Azikiwe University Teaching Hospital, Nnewi, Anambra State, Nigeria. ${ }^{4}$ Department of Paediatrics, Federal Teaching Hospital, Abakaliki, Ebonyi State, Nigeria. ${ }^{5}$ Department of Paediatrics, University of Nigeria Teaching Hospital, Ituku-Ozara, Enugu State, Nigeria.

Received: 14 October 2014 Accepted: 11 March 2015

Published online: 21 March 2015

\section{References}

1. United Nation Children Fund (UNICEF) 2013. Data: monitoring the situation of children and women. Neonatal mortality. Updated 2015. Retrieved and accessed on 17/01/2015 from data.unicef.org/child-mortlaity/neonatal.

2. The UN interagency Group report 2012. Levels and trends in child mortality. UNICEF Headquarters, New York; 2012.

3. Peter W, Karin K, Stefan P, Goran T, George W. Using the three delays model to understand why newborn babies die in eastern Uganda. Trop Med Int Health. 2010;15(8):964-72.

4. UNICEF millennium development goals 4: reduce child mortality. Assessed from http://www.unicef.org/mdg/childmortality.html.

5. United Nations Children's Fund UNICEF. Regional Office for South Asia surviving childbirth and pregnancy in south Asia. 2004; 11.

6. Shally A, Tuhina V, Monca A. Danger signs of neonatal illnesses: perceptions of caregivers and health workers in northern India. Bull World Health Organ. 2006;84:819-26.

7. Enugu State Government Official Website. About Enugu. Retrieved and accessed on 12/10/2014 from www.enugustate.gov.ng/aboutenugu.php.

8. Nigerian Population Commission. State and local government demographic profile: 2006. Abuja; 2010.

9. WHO, UNICEF. Caring for the newborn at home; a training course for community health workers; community health workers manual. Geneva; 2012.

10. Oyedeji GA. Socioeconomic and cultural background of hospitalized children in Ilesa, Nigeria. Nig J Paediatr. 1985;12:111-7.

11. Bhutta ZA, Darmstadt GL, Hasan BS, Haws RA. Community-based interventions for improving perinatal and neonatal health outcomes in developing countries: a review of the evidence. Pediatrics. 2005;115(2):519-617.

12. Dutta A, Dutta R. Recent advances in the diagnosis and management of neonatal sepsis. Daryaganj, New Delhi, India: Jaypee brothers Medical publisher; 2007. p. 78.

13. Dongre AR, Deshmukh PR, Garg BS. Awareness and health care seeking for newborn danger signs among mothers in peri-urban Wardha. Indian J Paediatr. 2009;76:691-3.

14. Awasthi S, Verma T, Agarwal M. Danger signs of neonatal illnesses: perceptions of caregivers and health workers in northern India. Bull World Health Organ. 2006;84(10):819-26.

15. Sandberg J, Odberg Pettersson K, Asp G, Kabakyenga J, Agardh A. Inadequate knowledge of neonatal danger signs among recently delivered women in south western rural Uganda: a community survey. PLoS One. 2014;9(5):1-9.

16. Baqui AH, Arifeen El, Darmstadt GL, Black ER, Santoshan M. Tinal report: formative research on newborn care practices in the home and pre-testing of alternative behaviours in Sylhet District, Bangladesh. November 2003. Baltimore, MD: Johns Hopkins Bloomberg School of Public Health; 2003.

17. Newborn Care: Danger signs in a newborn. NNF Teaching Aids. 2012.

18. World Health Organization 1999. Child health Research Project Special report. Retrieved from http://www.reproline.jhu.edu/english/2mnh/perinatal.pdf.

\section{Submit your next manuscript to BioMed Central and take full advantage of:}

- Convenient online submission

- Thorough peer review

- No space constraints or color figure charges

- Immediate publication on acceptance

- Inclusion in PubMed, CAS, Scopus and Google Scholar

- Research which is freely available for redistribution

Submit your manuscript at www.biomedcentral.com/submit 